\title{
The Influence of Structured Relief on Wetting Properties of Zinc Plated Steel Surface
}

\author{
A.V. Ryzhenkov, M.R. Dasaev, S.V. Grigoryev, A.V. Kurshakov \\ National Research University "Moscow Power Engineering Institute", Russia
}

\begin{abstract}
This work describes the studies on giving hydrophobic properties to zinc plated steel surface by relief texturizing using laser action. The main properties of hydrophobic surfaces are presented. Methods of surface generation with low wettability are considered. It has been established that the contact angle increases with atomic zinc portion on surface modified by laser texturizing. It has been detected that decrease in zinc portion and increase in iron portion on modified surface of zinc plated steel are a consequence of increase in laser power impact on the surface.
\end{abstract}

Key words: wettability, hydrophobic surfaces, roughness, relief, laser texturizing, contact angle of wetting.

\section{INTRODUCTION}

Hydrophobic properties of surface can be achieved by numerous methods: various coatings, surfactants, formation of microrelief on surface by laser impact, mechanical notching, chemical etching. The main properties of surface wetting are the contact angle $\theta$ and the sliding angle $\alpha$. The contact angle is defined as the angle between tangential to circumference formed by droplet and the surface where the droplet is located. At contact angle of $\theta>90^{\circ}$, the surface is hydrophobic, otherwise it is hydrophilic. Nowadays the hydrophobicity of functional surfaces is widely applied in various fields of science and engineering: decrease in pipeline hydraulic resistance, intensification of fluid condensation (for instance, in condensers of thermal power plants), decrease in ice adhesion and, as a consequence, surface protection against ice accumulation, etc. Another property of surface is sliding angle which indirectly determines the adhesion force of fluid and surface. Thus, a surface can be hydrophobic, however, the sliding angle could be sufficiently high.

At present laser impact onto surface is one of the most challenging methods of formation of hydrophobic surfaces due to their texturizing [1-2]. Numerous researchers proved positive effect of texturizing of ordered relief on various surfaces reflected in the form of decreased surface wetting. Formation of hydrophobic surfaces using laser ablation is mostly studied on aluminum, copper, and iron surfaces as well as on surfaces of various composite materials. Thus, on aluminum surfaces the contact angles are obtained from 150 to $176^{\circ}$ at the sliding angle of $2.3^{\circ}[1,3-6]$, on steel surfaces it is possible to obtain the contact angles from 130 to $160^{\circ}$ [7-8], on copper surfaces the contact angles are from 148 to $160^{\circ}$ [9-12]. The obtained results (contact and sliding angles) vary by different relief geometry and methods of subsequent surface processing. Thus, for instance, relief texturizing on aluminum surface with the line increment of $200 \mu \mathrm{m}$ using nanosecond laser and subsequent holding of samples at higher temperature in certain time results in surface hydrophobization with effective contact angle of $176^{\circ}$ and sliding angle of $6^{\circ}$ [9]. It should be mentioned that only in few publications sliding angle is measured in addition to contact angle.

We performed a set of studies on hydrophobization of brass and stainless steel surfaces using laser equipment. It is possible to obtain contact angels up to $147.64^{\circ}$ on stainless steel surface [13] and up to $145-146^{\circ}$ on brass surface [14].

As mentioned above, one of the effects obtained by surface hydrophobization is decrease in ice adhesion, hence, the use of hydrophobic surfaces allows to decrease the intensity of ice formation on surface. The issue of ice formation is important, for instance, in air heat recovery units (inflow exhaust ventilation). In such system there occurs heat exchange between hot warm air removed from rooms and cold air supplied in winter seasons. Heating of cold air makes it possible to decrease energy consumption of inflow exhaust system in winter seasons, thus increasing its efficiency. However, while heated air is cooled, moisture condensation and frost buildup take place on cold heat exchanging surface made usually of zinc coated steel, which in its turn leads to decrease in passage area of regenerator channels and increase in thermal resistance of heat exchange surface. Herewith, freezing can take place up to complete blockage of channel for heat air transportation causing emergency shutdown of inflow exhaust ventilation. A possible solution to the problem is hydrophobization of heat exchange zinc plated steel surface by means of laser texturizing of ordered relief. However, the results of similar studies are unavailable at present. 


\section{METHODS}

\subsection{General descriprtion}

This work studied zinc plated steel with the thickness of zinc coating up to $20 \mu \mathrm{m}$. Structured relief was made on the surface of samples made of this material by laser impact on the surface (laser ablation). Laser pulse acts locally on the surface, hence, in the contact point the pulse energy is absorbed resulting in material heating, fusion and evaporation of a part of the material (ablation). Depending on the parameters of laser radiation, the ablation can be based on various mechanisms, such as spallation, evaporation, breakage and fragmentation, therefore, the ablation material can be comprised of neutral atoms, ions, clusters, and nanoparticles. Herewith, major portion of molten metal moves from the center of contact spot to its periphery forming a cavity on its surface (Fig. 1) [14]. As a consequence of the mentioned processes, the surface cools down at very high rate and is solidified rapidly. Some of nanoparticles removed from the surface as a consequence of ablation are returned onto the surface and promote formation of multimodal roughness [14].

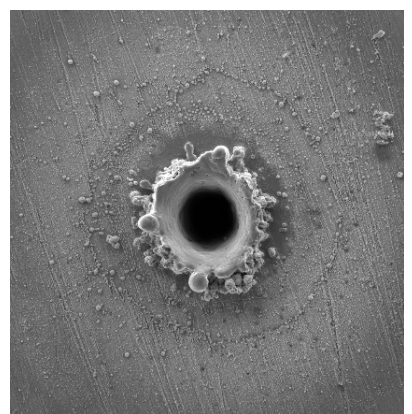

a)

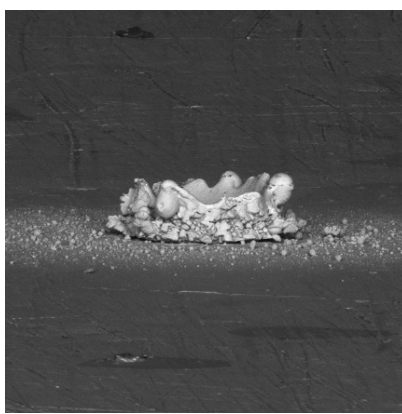

b)

Figure 1: Action of single laser pulse on metal surface: a) top view, b) side view.

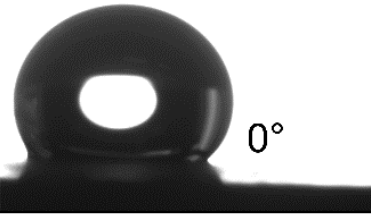

a)

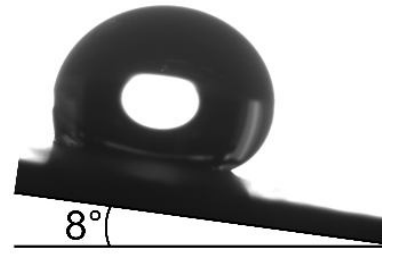

b)

Relief was formed on the sample surface using ytterbium fiber laser included into FMark NS-FB-20 assembly (OOO TsLT, Russia). The mentioned source of laser radiation is characterized as follows: wavelength $1064 \mathrm{~nm}$, laser power after MS-II-10 (RAYLASE AG, Germany) focusing system is $20 \mathrm{~W}$. Herewith, it is possible to vary the laser pulse duration from 4 to $200 \mathrm{~ns}$.

The contact and sliding angles were measured using DataPhysics OCA 20 system. A series of three measurements of contact angle (Fig. 2) and sliding angle (Fig. 3) was performed on each sample, then the average value was determined.

Elemental composition of the surface and atomic content of the elements were analyzed using a Tescan MIRA 3 LMU scanning electron microscope.

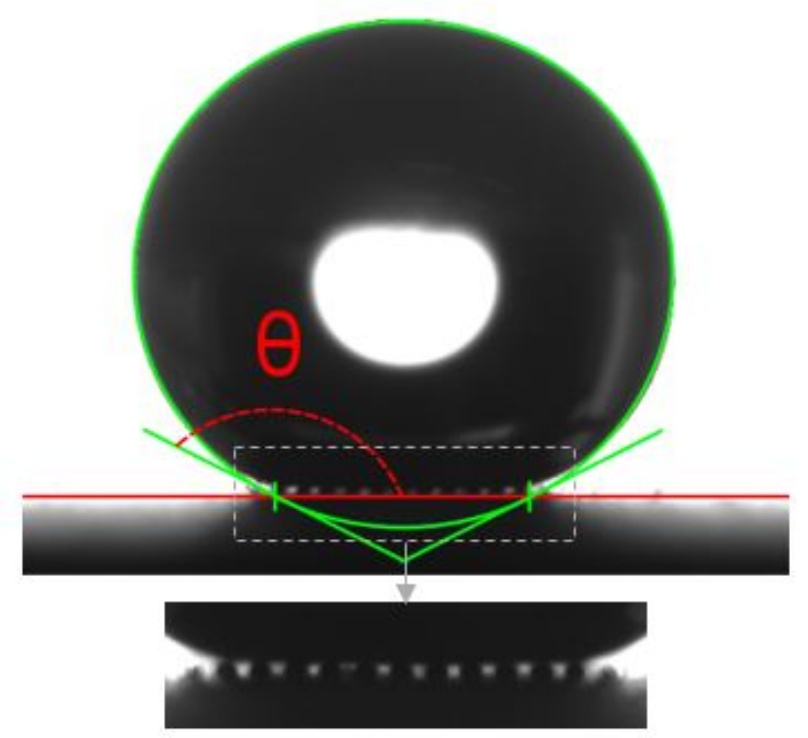

Figure 2: Contact angle of zinc plated steel surface with fluid textirized relief

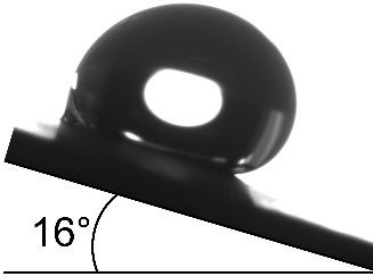

c)

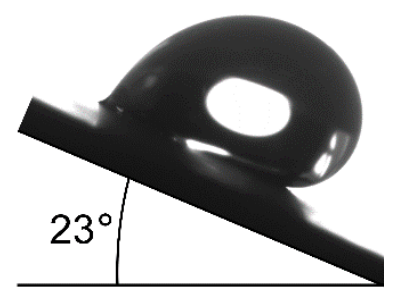

d)

Figure 3: Sliding angle on zinc plated steel: a) initial time, b) and c) surface deviation from horizontal, d) initiation of droplet shift on surface: sliding angle.

\subsection{Algorithm}

Experimental samples with the sizes of $30 \times 30 \mathrm{~mm}$ were made of zinc plated sheet steel aiming at subsequent formation of structured relief on their surfaces upon various properties of laser impact. Prior to the relief formation, the samples were washed in deionized water and cleaned by alcohol.
The prepared samples were placed onto positioning table in front of focusing system of laser unit, then the required parameters of laser impact were preset: scanning speed (travel speed of laser beam over sample surface) $\mathrm{v}=100,300$, and $500 \mathrm{~mm} / \mathrm{s}$, frequency of laser pulses $\mathrm{F}=20,50$, and $80 \mathrm{kHz}$, 
laser power $\mathrm{N}=50,75$, and $100 \%$ of rated value. The appearance of certain experimental samples is illustrated in Fig. 4. Since the laser beam travelled linearly over the surfaces, the formed relief was comprised of equally spaced grooves coated with material as a consequence of ablation (Fig. 5). It can be seen that decrease in scanning speed results in formation of deeper expressed grooves and increased coating material both inside and along the edges of the grooves.

After completion of relief formation, the elemental composition of the sample surface was determined and the surface morphology was analyzed using scanning electron microscope.

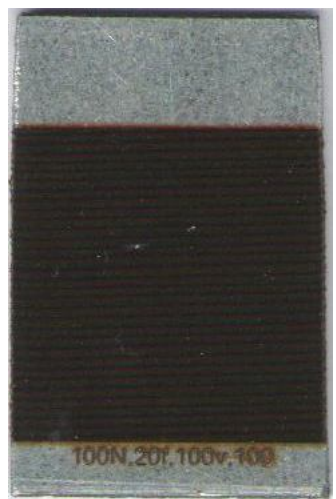

a)

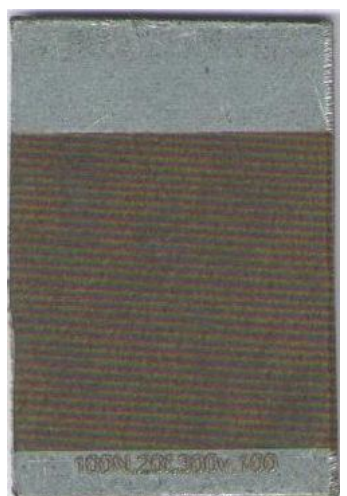

b)

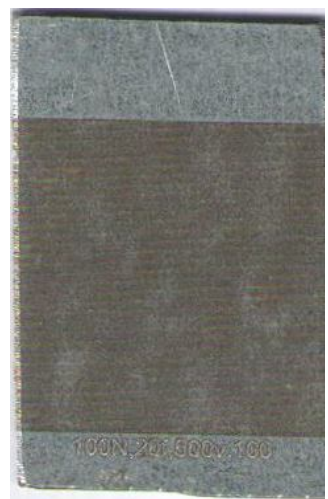

c)

Figure 4: Appearance of experimental samples of zinc plated steel at $100 \%$ laser power, $20 \mathrm{kHz}$ and at subsequent scanning speeds: a) $100 \mathrm{~mm} / \mathrm{s}$, b) $300 \mathrm{~mm} / \mathrm{s}$, c) $500 \mathrm{~mm} / \mathrm{s}$.
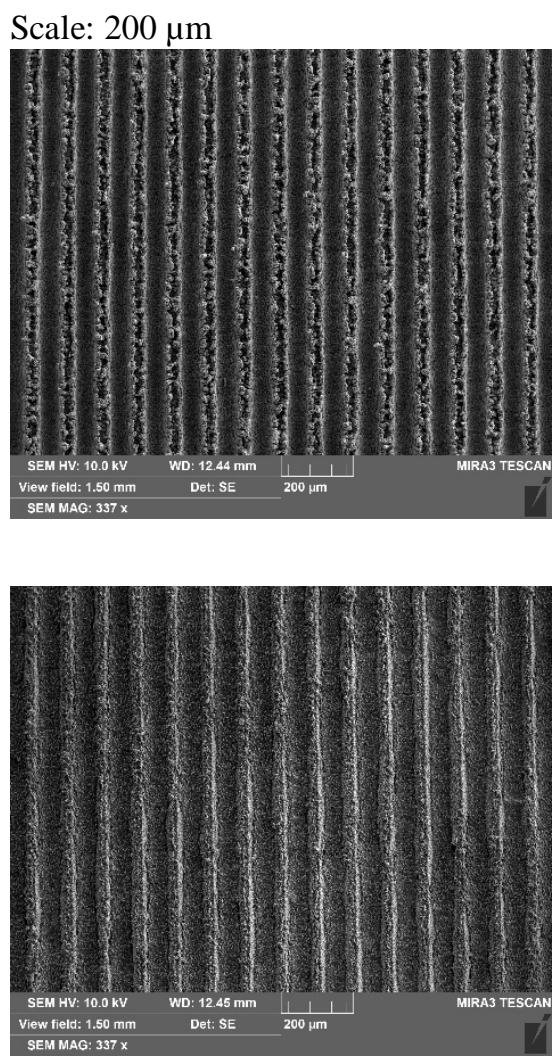

Scale: $100 \mu \mathrm{m}$

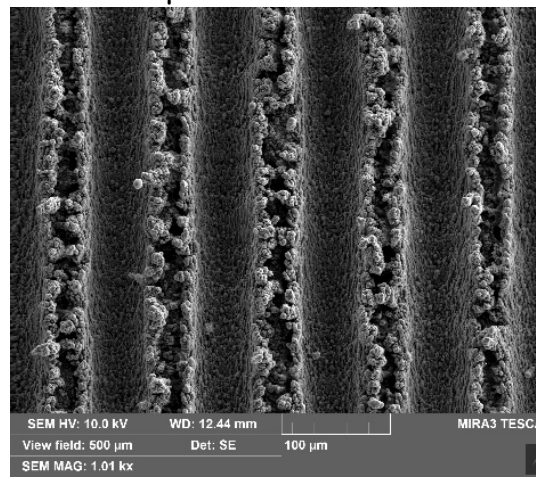

a)

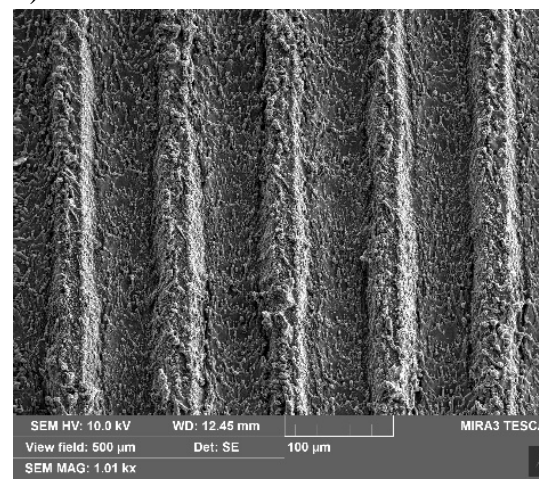

b)
Scale: $20 \mu \mathrm{m}$
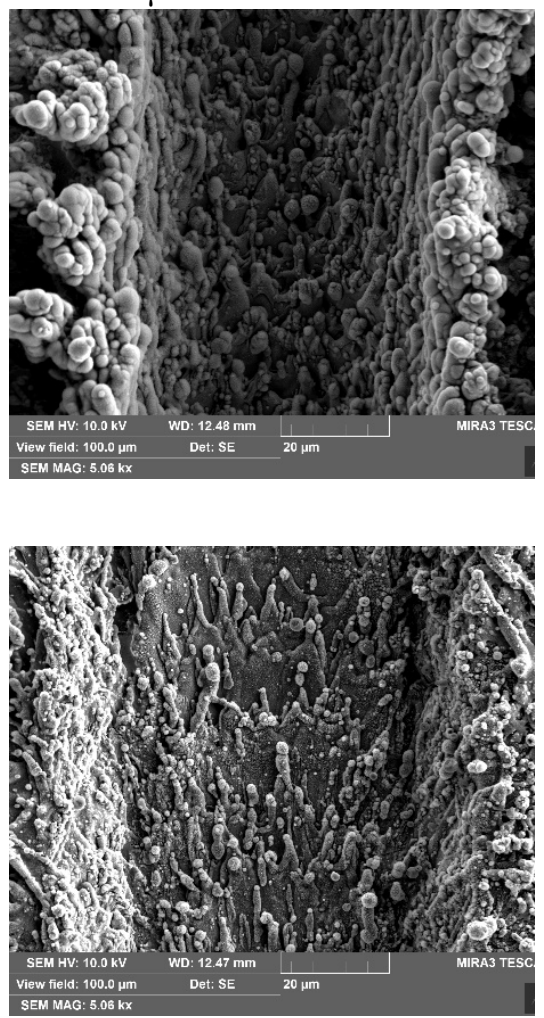


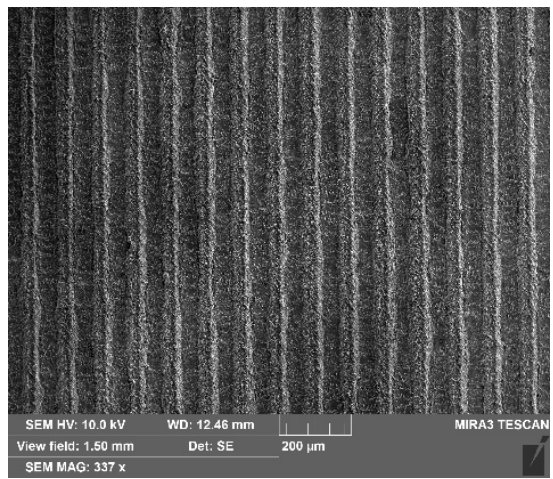

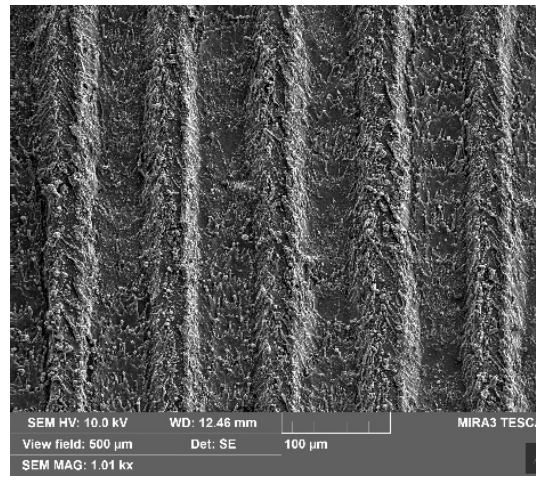

c)

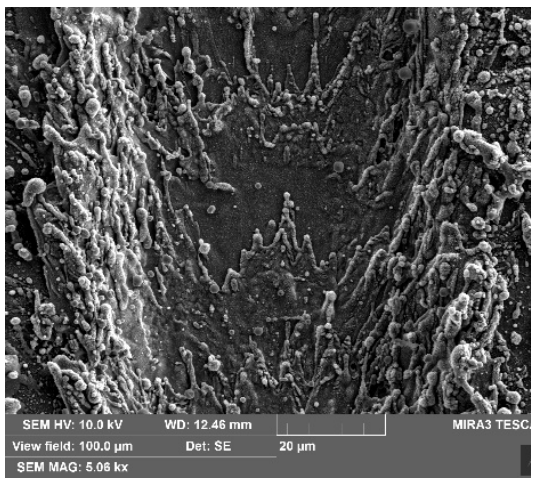

View field: $100.0 \mu \mathrm{m}$

Figure 5: Relief formed on zinc plated steel under $100 \%$ laser power, $20 \mathrm{kHz}$ and at subsequent scanning speeds: a) $100 \mathrm{~mm} / \mathrm{s}$, b) $300 \mathrm{~mm} / \mathrm{s}, \mathrm{c}) 500 \mathrm{~mm} / \mathrm{s}$.

Then the experimental samples were held indoors in 30 days which resulted in sorption of organic compounds on their surface [14], the surface became hydrophobic. After holding of samples in ambient environment, the contact angle and the sliding angle were measured.

\section{RESULTS AND DISCUSSION}

Surfaces with sufficiently high hydrophobicity were obtained by modification of experimental samples of zinc plated steel. Measurements of atomic content of the elements on sample surface, contact and sliding angles as a function of parameters of laser radiation are summarized in Table 1.

Table 1: Atomic content of elements in zinc plated steel samples and contact and sliding angles

\begin{tabular}{|c|c|c|c|c|c|c|c|c|c|c|c|}
\hline \multicolumn{3}{|c|}{ Parameters } & \multicolumn{7}{|c|}{ Atomic portions of elements, $\%$} & \multirow[b]{2}{*}{$\theta, \circ$} & \multirow[b]{2}{*}{$\alpha,{ }^{\circ}$} \\
\hline $\begin{array}{l}\mathbf{N}, \\
\%\end{array}$ & $\begin{array}{l}\mathbf{F}, \\
\text { kHz }\end{array}$ & $\begin{array}{l}\mathbf{v}, \\
\mathbf{m} / \mathbf{s}\end{array}$ & $\mathbf{O}$ & Al & $\mathbf{S i}$ & $\mathbf{P}$ & $\mathrm{Cr}$ & $\mathbf{F e}$ & $\mathbf{Z n}$ & & \\
\hline 50 & 20 & 100 & 32.85 & 0.40 & 0.00 & 0.29 & 0.00 & 41.49 & 24.97 & 50.56 & 50.90 \\
\hline 50 & 20 & 300 & 24.05 & 1.65 & 0.12 & 0.36 & 0.00 & 11.88 & 61.94 & 154.90 & 6.30 \\
\hline 50 & 20 & 500 & 31.70 & 1.08 & 0.00 & 0.57 & 0.32 & 0.00 & 66.33 & 155.28 & 8.40 \\
\hline 50 & 50 & 100 & 31.97 & 1.07 & 0.00 & 0.43 & 0.00 & 29.67 & 36.86 & 150.78 & 11.60 \\
\hline 50 & 50 & 300 & 24.04 & 1.49 & 0.00 & 1.41 & 0.97 & 26.07 & 46.02 & 152.67 & 1.60 \\
\hline 50 & 50 & 500 & 22.65 & 2.05 & 0.00 & 1.72 & 1.10 & 16.01 & 56.47 & 150.09 & 27.30 \\
\hline 50 & 80 & 100 & 27.46 & 2.62 & 0.00 & 1.33 & 0.89 & 12.82 & 54.88 & 152.20 & 4.50 \\
\hline 50 & 80 & 300 & 18.47 & 3.01 & 0.12 & 1.34 & 0.75 & 7.50 & 68.81 & 146.39 & 7.90 \\
\hline 50 & 80 & 500 & 28.53 & 2.90 & 0.00 & 2.86 & 1.84 & 0.00 & 63.87 & 140.04 & 88.80 \\
\hline 75 & 20 & 100 & 36.87 & 0.15 & 0.10 & 0.00 & 0.00 & 43.44 & 19.44 & 122.48 & -* \\
\hline 75 & 20 & 300 & 33.89 & 0.66 & 0.12 & 0.00 & 0.00 & 15.41 & 49.92 & 152.72 & 5.30 \\
\hline 75 & 20 & 500 & 33.06 & 1.05 & 0.00 & 0.60 & 0.00 & 2.64 & 62.65 & 149.22 & 6.10 \\
\hline 75 & 50 & 100 & 35.39 & 0.54 & 0.00 & 0.00 & 0.00 & 39.50 & 24.57 & 154.13 & 5.10 \\
\hline 75 & 50 & 300 & 24.03 & 0.46 & 0.11 & 0.38 & 0.00 & 45.05 & 29.97 & 153.02 & 21.00 \\
\hline 75 & 50 & 500 & 22.09 & 1.02 & 0.00 & 0.74 & 0.00 & 37.46 & 38.69 & 81.35 & $-*$ \\
\hline 75 & 80 & 100 & 33.45 & 1.06 & 0.00 & 0.63 & 0.00 & 30.28 & 34.58 & 143.41 & 8.30 \\
\hline 75 & 80 & 300 & 21.97 & 1.14 & 0.10 & 0.77 & 0.28 & 27.00 & 48.74 & 149.42 & 9.70 \\
\hline 75 & 80 & 500 & 23.03 & 1.64 & 0.00 & 1.17 & 0.91 & 25.09 & 48.16 & 150.58 & 5.20 \\
\hline 100 & 20 & 100 & 38.89 & 0.17 & 0.00 & 0.00 & 0.00 & 44.12 & 16.82 & 15.23 & $-*$ \\
\hline 100 & 20 & 300 & 33.73 & 0.59 & 0.00 & 0.00 & 0.00 & 21.34 & 44.34 & 150.74 & 12.80 \\
\hline 100 & 20 & 500 & 36.56 & 0.76 & 0.09 & 0.33 & 0.19 & 8.28 & 53.79 & 154.16 & 5.20 \\
\hline
\end{tabular}


A.V. Ryzhenkov et al., International Journal of Emerging Trends in Engineering Research, 8(1), January 2020, 164 - 169

\begin{tabular}{|l|l|l|l|l|l|l|l|l|l|l|l|}
100 & 50 & 100 & 43.97 & 0.20 & 0.00 & 0.11 & 0.00 & 24.86 & 30.86 & 112.92 & $-*$ \\
\hline 100 & 50 & 300 & 23.54 & 0.38 & 0.00 & 0.17 & 0.00 & 46.05 & 29.86 & 151.84 & 12.40 \\
\hline 100 & 50 & 500 & 20.57 & 0.94 & 0.00 & 0.34 & 0.00 & 28.02 & 50.13 & 152.14 & 9.80 \\
\hline 100 & 80 & 100 & 37.11 & 0.71 & 0.00 & 0.28 & 0.00 & 34.11 & 27.79 & 114.46 & $-*$ \\
\hline 100 & 80 & 300 & 27.53 & 0.69 & 0.00 & 0.63 & 0.00 & 40.87 & 30.28 & 124.23 & 57.70 \\
\hline 100 & 80 & 500 & 13.58 & 0.76 & 0.07 & 0.18 & 0.00 & 32.49 & 52.92 & 154.26 & 22.40 \\
\hline
\end{tabular}

Remark: * - sliding angle was not detected (a droplet does not roll off the surface at the inclination angle up to $90^{\circ}$ ).

Analysis of the experimental results has demonstrated that increase in duration of laser radiation (decrease in travel speed of laser beam while keeping other parameters of laser impact the same) on zinc plated steel surface leads to decrease in the atomic portion of $\mathrm{Zn}$ on the surface and increase in the portion of Fe. Probably such dependence is related with iron covering of $\mathrm{Zn}$ on the surface as a consequence of ablation. In addition, $\mathrm{Zn}$ can be carried over from the surface due to long-term impact of laser pulse and dispersed outside the sample surfaces in cooled state in the form of granules (particles). That is, upon increase in time of laser radiation, Fe layer can be formed on zinc plated steel surface up to complete covering of zinc coating with iron.

Analysis of the measured contact and sliding angles of the surface has revealed that the angles increase with atomic $\mathrm{Zn}$ content on the surface (Fig. 6). It is obvious that the effective contact angle of zinc plated steel surface is up to $154^{\circ}$, herewith, the minimum sliding angle is $1.6^{\circ}$.

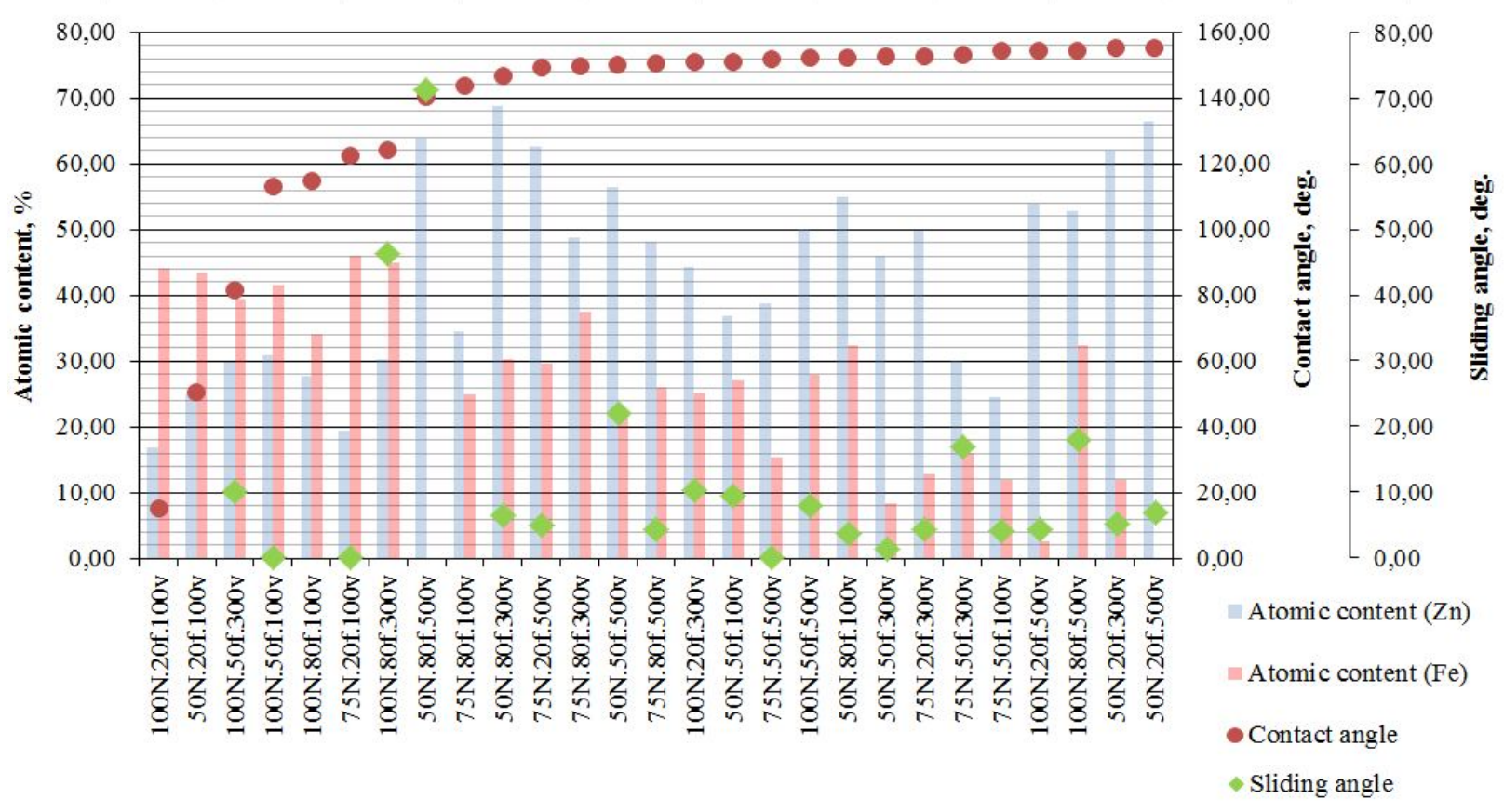

Figure 6: Contact and sliding angles as a function of atomic portion of iron $(\mathrm{Fe})$ and zinc $(\mathrm{Zn})$ in the surface composition

\section{CONCLUSION}

It has been determined that the increase in impact duration of laser radiation (decrease in travel speed of laser beam while keeping other parameters of laser impact the same) on zinc plated steel surface leads to decrease in the atomic portion of $\mathrm{Zn}$ on the surface and increase in the portion of Fe, the contact angle also decreases.

It has been established that the contact angle of zinc plated steel surface modified by fluid using laser ablation is up to $154^{\circ}$, herewith, the minimum sliding angle is $1.6^{\circ}$.

\section{ACKNOWLEDGEMENT}

This work was supported by the Ministry of Education and Science of the Russian Federation, project No. 13.9609.2017/8.9 titled: Development of innovative engineering solutions to creation of multiscale ordered relief on internal pipe surfaces aimed at decrease in hydraulic losses upon transportation of fluids. 


\section{REFERENCES}

1. L.B. Boinovich, A.M. Emelyanenko, A.D. Modestov, A.G. Domantovsky, A.A. Shiryaev, K.A. Emelyanenko, O.V. Dvoretskaya, A.A. Ganne. Corrosion behavior of superhydrophobic aluminum alloy in concentrated potassium halide solutions: When the specific anion effect is manifested. Corrosion Science, vol. 112, pp. 517-527, 2016. https://doi.org/10.1016/j.corsci.2016.08.019

2. U. Trdan, M. Hočevar, P. Gregorčič. Transition from superhydrophilic to superhydrophobic state of laser textured stainless steel surface and its effect on corrosion resistance. Corrosion Science, vol. 123, pp. 21-26, 2017.

https://doi.org/10.1016/j.corsci.2017.04.005

3. C.V. Ngo, D.M. Chun. Control of laser-ablated aluminum surface wettability to superhydrophobic or superhydrophilic through simple heat treatment or water boiling post-processing. Applied Surface Science, vol. 435, pp. 974-982, 2018.

https://doi.org/10.1016/j.apsusc.2017.11.185

4. Z. Lei, Z. Tian, X. Chen, Y. Chen, J. Bi, S. Wu, H. Sun. Large spot diameter nanosecond laser treatment of aluminum alloy sheets for high-speed superhydrophobic hierarchical micro- and nanostructured surface preparation. Surface and Coatings Technology, vol. 361, pp. 249-254, 2019.

5. J. Li, S. Zhao, F. Du, Y. Zhou, H. Yu. One-step fabrication of superhydrophobic surfaces with different adhesion via laser processing. Journal of Alloys and Compounds, vol. 739, pp. 489-498, 2018. https://doi.org/10.1016/j.jallcom.2017.12.252

6. V. Vercillo, J.T. Cardoso, D. Huerta-Murillo, S. Tonnicchia, A. Laroche, J.A.Mayén Guillén, J.L. Ocaña, A.F. Lasagni, E. Bonaccurso. Durability of superhydrophobic laser-treated metal surfaces under icing conditions. Materials Letters: X, vol. 3, 2019.

7. P. Bizi-bandoki, S. Valette, E. Audouard, S. Benayoun. Time dependency of the hydrophilicity and hydrophobicity of metallic alloys subjected to femtosecond laser irradiations. Applied Surface Science, vol. 273, pp. 399-407, 2013.

8. Q. Ma, Zh. Tong, W. Wang, G. Dong. Fabricating robust and repairable superhydrophobic surface on carbon steel by nanosecond laser texturing for corrosion protection. Applied Surface Science, vol. 455, pp. 748-757, 2018.

https://doi.org/10.1016/j.apsusc.2018.06.033

9. D.M. Chun, C.V. Ngo, K.M. Lee. Fast fabrication of superhydrophobic metallic surface using nanosecond laser texturing and low-temperature annealing. CIRP Annals, vol. 65, no. 1, pp. 519-522, 2016.

10. S. Sarbada, Y.C. Shin. Superhydrophobic contoured surfaces created on metal and polymer using a femtosecond laser. Applied Surface Science, vol. 405, pp. 465-475, 2017.
11. H. Yan, M.R.B. Abdul Rashid, S.Y. Khew, F. Li, M. Hong. Wettability transition of laser textured brass surfaces inside different mediums. Applied Surface Science, vol. 427, Part B, pp. 369-375, 2018. https://doi.org/10.1016/j.apsusc.2017.08.218

12. J. Long, Z. He, C. Zhou, X. Xie, Z. Cao, P. Zhou, Y. Zhu, W. Hong, Z. Zhou. Hierarchical micro- and nanostructures induced by nanosecond laser on copper for superhydrophobicity, ultralow water adhesion and frost resistance. Materials \& Design, vol. 155, pp. 185-193, 2018.

13. A.V. Ryzhenkov, M.R. Dasaev, S.V. Grigoriev, A.V. Kurshakov, A.F. Mednikov, O.V. Ryzhenkov. Hydrophobization of Metal Surfaces. International Journal of Recent Technology and Engineering, vol. 8, no. 4, pp. 6715-6720, 2019. https://doi.org/10.35940/ijrte.D8554.118419

14. A.V. Ryzhenkov, M.R. Dasaev, S.V. Grigoriev, A.V. Kurshakov, O.V. Ryzhenkov, M.V. Lukin. Hydrophobic brass surfaces created by means of multi-scale relief. International Journal of Mechanical Engineering and Technology, vol. 9, no. 58-70, 58-70, 2018. 